\title{
Gestão Ambiental sob a Ótica de um Centro Automotivo: um estudo de caso na cidade de Santa Maria/RS
}

\author{
Environmental Management under the Perspective of an Automotive Center: a case study in the city of Santa Maria/RS
}

\author{
Daniel Lazarotto', Thiago Kader Rajeh Ibdaiwi², Damiana Machado de Almeida ${ }^{3}$, Vânia Medianeira Flores Costa ${ }^{4}$, Luis \\ Felipe Dias Lopes ${ }^{5}$, Rita de Cássia Trindade dos Santos ${ }^{6}$ \\ ' Bacharel em Administração, Faculdade Metodista de Santa Maria, Santa Maria, Brasil. \\ ${ }^{2}$ Mestrado em Engenharia de Produção pela UFSM, Professor da Faculdade Metodista de Santa Maria, Bacharel em Administração, Faculdade \\ Metodista de Santa Maria, Santa Maria, Brasil. \\ ${ }^{3}$ Mestranda em Administração, Universidade Federal de Santa Maria, Santa Maria, Brasil. \\ ${ }^{4}$ Doutora em Administração pela UFBA, Professora adjunta do Departamento de Ciências Administrativas, Universidade Federal de Santa Maria, \\ Santa Maria, Brasil. \\ ${ }^{5}$ Doutor em Engenharia de Produção pela UFSC, Professor associado, Universidade Federal de Santa Maria, Santa Maria, Brasil. \\ ${ }^{6}$ Acadêmica de Administração, Universidade Federal de Santa Maria, Santa Maria, Brasil.
}

\section{Resumo}

Para as empresas ligadas ao setor automobilístico a preocupação com o meio ambiente é primordial, principalmente por gerar grande quantidade e variedade de resíduos prejudiciais ao meio ambiente. Para Andrade et al (2002), uma das estratégias para essas organizações é aprimorar seus processos produtivos, com a eliminação/redução de perdas e geração de resíduos ao longo da cadeia de valor. O objetivo desse estudo é de identificar a aplicabilidade de um programa de gestão ambiental em um Centro Automotivo localizado na cidade de Santa Maria/RS. Para isso realizou-se uma pesquisa de cunho bibliográfica e descritiva, de abordagem qualitativa tendo como estratégia o estudo de caso. A coleta de dados foi realizada por meio de entrevista semiestruturada junto ao gestor da empresa e questionário previamente estruturado aplicado aos colaboradores. Os resultados obtidos mostram que a empresa procura descartar resíduos de forma ambientalmente correta, ainda que necessite aprimorar esses processos. Em relação à implementação do SGA, faz-se importante mensurar os custos com todos os benefícios proporcionados à empresa, tais como, reforço de uma imagem positiva da empresa, conformidade perante as leis ambientais, ambiente de trabalho limpo e seguro, redução do risco de acidentes e do descarte inapropriado de resíduos..

Palavras-chave: Gestão Ambiental, Centro Automotivo, Resíduos, Sistema de Gestão Ambiental (SGA)..

\begin{abstract}
For companies linked to the auto industry, the concern for the environment is paramount, especially for generating large quantities and variety of environmentally harmful waste. Andrade et al (2002), one of the strategies for these organizations is to improve their production processes, with the elimination/reduction of losses and waste generation throughout the value chain. The aim of this study is to identify the applicability of an environmental management program in a Automotive Center located in Santa Maria/RS. For this we carried out a survey of bibliographic and descriptive nature of qualitative approach with the strategy case study. Data collection was conducted through semi-structured interviews with the manager of the company and previously structured questionnaire administered to employees. The results obtained show that the company seeks to dispose waste in an environmentally friendly way, still needing enhance these processes. Regarding the implementation of the EMS - is it important to measure the cost of all benefits provided to the company, such as reinforcing a positive image of the company, before compliance with environmental laws, clean and safe work environment, reducing the risk of accidents and waste disposal .
\end{abstract}




\section{INTRODUÇÃO}

Em décadas passadas, as empresas orientavam-se apenas em manter um modelo de gestão voltada para atender a demanda do mercado com o menor custo possível, ou seja, não considerava o bem estar de seus colaboradores, da sociedade envolvida no processo, e muito menos com os danos ambientais.

Anderson (1982 apud DONAIRE, 2009) afirma que a principal alteração verificada é a percepção das corporações sobre o papel que desempenham na sociedade. As empresas não são mais vistas com propósitos simplesmente econômicos, e voltadas apenas ao desenvolvimento e venda de seus produtos e serviços assumindo também uma função significativa no favorecimento da qualidade de vida nas comunidades nas quais estão inseridas.

Além disso, com as alterações climáticas, a escassez de recursos e as catástrofes que vem acontecendo frequentemente, a humanidade e principalmente as organizações estão buscando uma nova postura perante a natureza. Para as empresas ligadas ao setor automobilístico a preocupação com o meio ambiente, não é diferente, as mesmas devem ter uma atenção especial, pois elas são responsáveis por gerar grande quantidade e variedade de resíduos prejudiciais ao meio ambiente e consequentemente a qualidade de vida.

Assim, o automóvel, o desejo de consumo de muitos e razão da existência dessas empresas, é considerado um dos responsáveis por grande parte dos problemas ambientais do planeta, porém, nos dias de hoje é um bem que parece ser indispensável para atender os anseios do homem moderno. Segundo Trigueiro (2005, p. 102), "um dos grandes problemas ambientais do planeta é, curiosamente, uma das maiores paixões da humanidade. O século vinte foi marcado pelo 'boom do automóvel', que se transformou num sonho de consumo da era moderna".

Para Gomes et al. (2008) é pouco provável que o consumidor deixe de adquirir um automóvel mesmo tendo consciência do fato. Portanto, o desafio é saber o que fazer com os resíduos indesejáveis desse consumo e encontrar uma solução para reduzir os danos causados ao meio ambiente. Andrade et al (2006) afirmam que uma das estratégias para organizações que pertencem a esse setor econômico é estabelecer a criação e aprimoramento de seus processos produtivos, com a eliminação/redução de perdas e geração de resíduos ao longo da cadeia de agregação de valores.

Conforme relatório divulgado pela Agência Portuguesa do Ambiente, a Gestão Ambiental e Inovação tem como objetivos: a) Promover a ecoeficiência das organizações; b) Incentivar a adoção de padrões de produção e consumo mais compatíveis com um comportamento sustentável, dissociando o crescimento econômico da degradação ambiental; c) Estimular a oferta e a procura de produtos, atividades e serviços com impacto ambiental reduzido, contribuindo para o desenvolvimento sustentável; d) Melhorar o desempenho ambiental das atividades econômicas e incentivar as boas práticas ambientais no seio das organizações; e) Fomentar o diálogo com todas as partes interessadas sobre o desempenho ambiental das organizações e assegurar o envolvimento dos colaboradores nas questões ambientais associadas (RELATÓRIO DO ESTADO DO MEIO AMBIENTE, REA 2013, p.185)

Considerando que a implementação de um programa de gestão ambiental é uma importante oportunidade de adequação as exigências mercadológicas atuais para todos os tipos de organizações, em especial as que estão situadas em uma condição mais crítica em relação a resíduos e descartes como as oficinas mecânicas, o desenvolvimento dessa pesquisa partiu da seguinte problemática de estudo: Quais os benefícios que a implementação de um programa de gestão ambiental pode proporcionar ao Centro Automotivo?

Assim o presente estudo tem como objetivo geral identificar a aplicabilidade de um programa de gestão ambiental em um Centro Automotivo localizado na cidade de Santa Maria/RS. Com o propósito de atingir o objetivo geral analisaram-se os seguintes objetivos específicos: analisar na literatura aspectos importantes sobre meio ambiente e gestão ambiental empresarial; identificar quais os principais resíduos resultantes do processo produtivo deste tipo de empresa; descrever os procedimentos de descarte de resíduos utilizados pelo Centro Automotivo; verificar se os procedimentos de descartes de resíduos utilizados levam em consideração as preocupações ambientais; apresentar os benefícios que um programa de gestão ambiental pode proporcionar ao Centro Automotivo.

\section{MÉTODO}


Segundo Marconi, Lakatos, (2010, p. 204) "a especificação da metodologia da pesquisa é a que abrange maior número de itens, pois responde, a um só tempo, às questões Como? Com quê? Onde? Quanto?". Metodologia são os procedimentos utilizados na realização da pesquisa, sua organização varia de acordo com o aspecto de cada pesquisa, conforme as informações obtidas (GIL, 2009).

O presente estudo se caracteriza com uma pesquisa de cunho bibliográfica e descritiva. A caracterização da pesquisa é bibliográfica, ou seja, um estudo de fontes secundárias com objetivo de reunir informações e conhecimentos sobre gestão ambiental. Descritiva porque busca identificar e descrever os benefícios que um sistema de gestão ambiental pode trazer para o Centro Automotivo.

A pesquisa bibliográfica se refere ao embasamento teórico realizado por meio de pesquisas em livros e artigos acadêmicos de diversos autores. A pesquisa tem por objetivo fundamental descobrir respostas para problemas, mediante o emprego de procedimentos científicos (GIL, 2008).

Para Köche (1997, p. 122), o "objetivo da pesquisa bibliográfica, portanto, é o de conhecer e analisar as principais contribuições teóricas existentes sobre um determinado tema ou problema, tornando-se um instrumento indispensável para qualquer tipo de pesquisa".

Já a pesquisa descritiva segundo Cervo, Bervian e Silva (2007, p.61)

observa, registra, analisa e correlaciona fatos ou fenômenos (variáveis) sem manipulá-los. Procura descobrir, com a maior precisão possível, a frequência com que um fenômeno ocorre, sua relação e conexão com outros, sua natureza e suas características.

A abordagem de pesquisa desenvolvida para coleta dos dados foi à qualitativa, pois as informações coletadas procuraram responder como, de que maneira acontecem os procedimentos referentes ao descarte de resíduos da empresa. Segundo Marconi e Lakatos (2007), a pesquisa qualitativa possui como base a presença ou a ausência de algo como a qualidade ou características, caracterizadas pelo alto grau de complexidade interno.

Pelo fato da pesquisa ser do tipo descritiva, foi utilizado como estratégia o estudo de caso. Segundo Yin (2005) o estudo de caso permite uma investigação para se preservar as características holísticas e significativas dos acontecimentos da vida real - tais como ciclos de vida individuais, processos organizacionais e administrativos, mudanças ocorridas em regiões urbanas, relações internacionais e a maturação de setores econômicos.

Desse modo, o estudo de caso serviu para investigar e conhecer os processos e os procedimentos que o Centro Automotivo utiliza para o descarte dos resíduos resultante das atividades da empresa, assim como a percepção do proprietário e colaboradores no que diz respeito a gestão ambiental, com o intuito de demonstrar os benefícios que um sistema de gestão ambiental pode trazer à empresa.

O instrumento para coleta de dados dividiu-se em duas etapas, a realização de uma entrevista com o proprietário do Centro Automotivo, e também a aplicação de um questionário aos seus respectivos colaboradores. Para Yin (2005, p.116) "uma das mais importantes fontes de informações para um estudo de caso são as entrevistas". Essa entrevista foi semi-estruturada, onde o proprietário respondeu a sete (7) questões abertas referente a gestão ambiental e descarte de resíduos da empresa. Segundo Triviños (2007, p.145), "para alguns tipos de pesquisa qualitativa, a entrevista semi-estruturada é um dos principais meios que tem o investigador para realizar a coleta de dados".

Logo após a realização da entrevista, deu-se continuidade a pesquisa juntamente com os colaboradores da empresa, através de um questionário previamente estruturado com perguntas abertas e fechadas relacionadas com o objetivo do estudo, porém distribuído aos 12 colaboradores do Centro Automotivo, obtendo 100\% de participação. Segundo Cervo, Bervian e Silva (2007, p.53) "o questionário é a forma mais usada para coletar dados, pois possibilita medir com mais exatidão o que se deseja".

A interpretação dos dados foi realizada com cunho qualitativo, visando transcrever os dados na íntegra conforme os respondentes, para tanto, foi realizada uma análise descritiva sem a identificação dos colaboradores participantes os quais foram denominados de sequência numérica. Para melhor visualização os dados serão apresentados em forma de tabela.

\section{REVISÃO DA LITERATURA}

No intuito de compor um arcabouço teórico que possibilitasse um embasamento científico para o presente estudo, optou-se por subdividir esse capítulo em: Gestão Ambiental, Sistemas de Gestão Ambiental, Certificação ISO 14001 e Gestão Ambiental Empresarial. 


\subsection{Gestão ambiental}

Segundo Dias (2009), o processo de intensificação da capacidade humana de intervir no ambiente natural foi se desenvolvendo de forma gradativa e cumulativa, mas durante muito tempo às modificações provocadas, aparentemente, não foram significativas se comparadas as dos dias atuais.

Nas últimas décadas tem ocorrido uma mudança muito grande no ambiente de atuação das empresas, sendo que elas eram vistas apenas como instituições econômicas com o objetivo de resolver problemas econômicos fundamentais (o que produzir, como produzir e para quem produzir), porém, hoje observa-se o surgimento de novos papéis que devem ser desempenhados, como resultado das alterações no ambiente em que operam (DONAIRE, 2009).

Surge do ponto de vista empresarial a Gestão Ambiental, expressão utilizada para se denominar a administração que se orienta para evitar, na medida do possível, problemas para o meio ambiente. Para Barbieri (2006) como gestão ambiental entende-se as diretrizes e as atividades administrativas e operacionais, tais como planejamento, direção, controle, alocação de recursos e outras realizadas com o objetivo de obter efeitos positivos sobre o meio ambiente, que sendo reduzindo ou eliminando os danos ou problemas causados pelas ações humanas, ou evitando que eles degradem o ambiente.

Em outras palavras como explica Dias (2009) é a gestão que objetiva conseguir que os efeitos ambientais não ultrapassem a capacidade de carga do meio onde se encontra a organização, ou seja, obter um desenvolvimento sustentável em seu processo produtivo. Logo, pode-se dizer que gestão ambiental é um modelo de gerenciamento que uma empresa ou organização estabelece para administrar suas atividades e seus processos de modo a não causar danos ou pelo menos minimizar a degradação do meio ambiente na qual está inserida.

Entre muitas definições encontradas, Nilsson (1998 apud CORAZZA, 2003, p.4):

Gestão ambiental envolve planejamento, organização, e orienta a empresa a alcançar metas ambientais específicas, em uma analogia, por exemplo, com o que ocorre com a gestão de qualidade. Um aspecto relevante da gestão ambiental é que sua introdução requer decisões nos níveis mais elevados da administração e, portanto, envia uma clara mensagem à organização de que se trata de um compromisso corporativo. A gestão ambiental pode se tornar também um importante instrumento para as organizações em suas relações com consumidores, o público em geral, companhias de seguro, agências governamentais.

A partir desses pressupostos, nota-se que a gestão ambiental utiliza de modernas práticas de gerenciamento numa atuação empresarial mais responsável e baseada em um desenvolvimento econômico e social sustentável. E o sucesso de sua implementação dependerá de como o administrador ou empreendedor irá desenvolver o discernimento dentro da organização. Isso significa que se a atitude e a consciência ambientalmente correta partir do mais alto nível hierárquico da organização e difundir-se para os níveis inferiores de forma eficaz, certamente as diretrizes de gestão ambiental ficarão fortemente inseridas na imagem dessa organização.

Para Pinheiro e Oliveira (2010), uma das alternativas utilizadas pelas empresas para responderem as demandas de modernização de seus sistemas de gestão, qualificação de seus produtos, inovações tecnológicas, sustentabilidade competitividade e consequente lucratividade tem sido os Sistemas de Gestão Ambiental.

\subsection{SISTEMAS DE GESTÃo AMBIENTAL (SGA)}

"Sistema de gestão ambiental é um conjunto de atividades administrativas e operacionais inter-relacionadas para abordar os problemas ambientais atuais ou para evitar o seu surgimento" (BARBIERI, 2006, p.137).

Conforme as normas da ABNT (2004), os Sistemas de Gestão Ambiental são constituídos de normas globais de gerenciamento com a finalidade de ordenar e conscientizar as organizações que possuem preocupações ambientais, através de alocações de recursos, definições de responsabilidades e avaliação contínua de práticas, procedimentos e processos, voltados para desenvolver, implementar, atingir, analisar criticamente e manter a política ambiental estabelecida pela empresa.

Segundo Reis e Queiroz (2002), as normas direcionadas as organizações proporcionam um abrangente guia para o estabelecimento, manutenção e avaliação de um Sistema de Gestão Ambiental (SGA), pois ajudam a organização a encontrar informações de que precisam, servindo como base para seu planejamento, tomada de decisões e comunicação de informações específicas ambientais.

Na visão de Barbieri (2006), a empresa pode criar o seu próprio SGA ou adotar um dos modelos 
genéricos propostos por entidades nacionais ou internacionais, a criação e a operação de um SGA, próprio ou baseado num modelo genérico, podem se consideradas uma espécie de acordo voluntário unilateral, desde que a empresa se comprometa a alcançar um desempenho superior ao exigido pelas leis ambientais.

Para Neto et al (2008) a fim de que o SGA tenha sucesso em sua implementação tendo a gestão ambiental como parte da organização, é importante dentre outras questões: a) incluir a gestão ambiental como prioridade; $b$ ) identificar os requisitos legais e outros aplicáveis as atividades, produtos e serviços da empresa; c) avaliar e monitorar o desempenho ambiental; d) promover a harmonização do SGA com outros sistemas de gestão, além de promover o envolvimento de todos na força de trabalho.

O autor ainda destaca quais são os benefícios da implementação de um sistema de gestão ambiental para o meio ambiente, para a empresa, para os clientes, para os funcionários e para a comunidade conforme se observa na Figura 01.

\section{Para a empresa}

- Criação de imagem "ecológica"

- Controle de seus impactos ambientais

- Acesso a novos mercados

- Melhora na competitividade

- Otimização de Recursos

- Menor risco de sanções do poder

Para o meio ambiente

- Racionalização do uso das matérias-primas e outros insumos

- Conservação dos recursos naturais

- Diminuição e controle de poluentes

- Harmonizacão das atividades

\section{Para a comunidade}

- Atendimento a legislação pertinente

- Redução da poluição

- Maior segurança

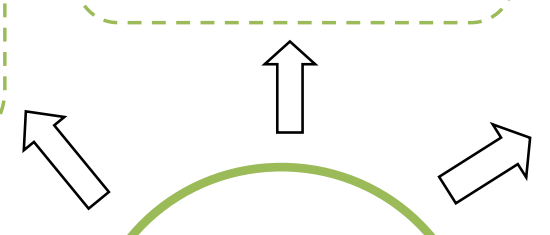

Implantação de um sistema de gestão ambiental

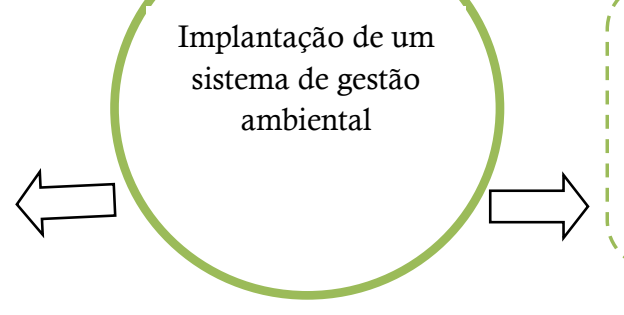

Para os clientes

- Confiabilidade na sustentabilidade do produto - Credibilidade na empresa por sua atuação responsável - Cuidados com a disposição final do produto

- Incentivos a reciclagem do

\section{Para os funcionários}

- Conscientização ambiental

- Melhor condição de trabalho

- Maior Segurança

- Comprometimento com o

moin amhiente

Figura 01 - Benefícios da implantação de um sistema de gestão ambiental

Fonte: Neto (2008 p.84)

Seguindo essa linha de raciocínio, Wendler (2009) diz que a aplicação de um SGA contribui para o sucesso das organizações pois sua implementação traz benefícios tais como: promove em curto período de tempo a redução dos custos através da economia do consumo de recursos e da minimização e controle da geração de resíduos; permite acesso a mercados restritos; melhora significativamente a imagem da empresa frente a comunidade e o mercado em geral; minimiza o risco de multas e processos na justiça; facilita a obtenção de financiamentos em bancos e ainda reduz custos de seguro. Também é importante salientar que a implementação do SGA não levará de imediato à otimização do processo produtivo, já que sua base é o comprometimento com a melhoria contínua.

De modo geral, é possível verificar uma determinada diferenciação entre as empresas que adotam algum SGA, seja nos seus produtos ou em seus serviços. Isso se deve ao fato que as empresas que utilizam um SGA realizam suas atividades de forma padronizada, pois o desenvolvimento de qualquer processo, e em qualquer setor deve seguir as normas pré-estabelecidas pela empresa que optou por um SGA compatível a sua estrutura (DIAS, 2009). E o resultado dessa padronização é de fácil percepção, principalmente por aquele cliente que tem certa preocupação com o meio ambiente, ou com a qualidade de vida.

Logo, observar-se segundo Donaire (2009) que um aumento da consciência ambiental da população, ou mais precisamente do consumidor que mais frequentemente procura produtos e serviços com 
certificados que comprovem a preocupação ambiental das empresas. Um exemplo disso é o grande aumento de organizações com a certificação da série ISO 14.001, considerado uma norma que serve como base para implementação de muitos SGA.

\subsection{Certificação ISO I4.00I}

No dia 23 de fevereiro de 1947, com sede em Genebra na Suíça foi fundada a ISO - International Organization for Standardization (Organização Internacional) com a finalidade de elaborar normas internacionais, e que ficou conhecida mundialmente através da ISO 9000, um conjunto de normas que se referem aos Sistemas de Gerenciamento da Qualidade na Produção de Bens de Consumo ou Prestação de Serviços (DONAIRE, 2009).

Devido ao fato do crescente desenvolvimento industrial e econômico as autoridades ligadas ao meio ambiente obrigaram-se a elaborar novas normas e recomendações, a exemplo disso as normas da série ISO 14.000. Sendo assim, muitas empresas presentes no mercado adotaram seus Sistemas de Gestão Ambiental baseado nessas normas. Reis e Queiroz (2002, p. 24) definem as normas da série ISO 14000 como: "um conjunto de normas ou padrões de gerenciamento ambiental, de caráter voluntário, que podem ser utilizadas pelas empresas para demonstrar que possuem um sistema de gestão ambiental".

De acordo com Kraemer (2002, p.51), "o conjunto de normas ISO 14000 compartilha princípios comuns de sistemas de gestão com a série de normas ISO 9000 para sistemas de qualidade, tais como a definição de uma política, procedimentos, objetivos e metas, entre outros". Para Reis e Queiroz (2002, p.25), as normas da série ISO 14000 foram desenvolvidas tendo como principais objetivos: a) Proporcionar meios ou condições para um melhor gerenciamento ambiental, b) Ser aplicável a todos os países, c) Promover, da forma mais abrangente possível, a harmonia entre o interesse público e os dos usuários das normas, d) Possui uma base científica e e) Ser prática, útil e utilizável.

Dentro desse contexto, surge a demanda de empresas que buscam um Sistema de Gestão Ambiental (SGA) que possa ser aplicado no gerenciamento e controle das ações das empresas sobre o ambiente. Assim, a implantação de um SGA, ou mais precisamente a norma NBR ISO 14001, faz com que o processo produtivo seja reavaliado continuamente, refletindo na busca por procedimentos, e padrões comportamentais menos nocivos ao meio ambiente (CAMPOS et al., 2006).

A implementação de um SGA, segundo a ISO 14001, exige o cumprimento de requisitos normativos que devem ser estruturados de forma a se estabelecer um sistema de melhoria contínua. Conforme a ABNT (2004) o SGA proposto deve cumprir requisitos quanto a: a) Política ambiental; b) Planejamento; c) Implementação e operação; d) Verificação e ação corretiva e e) Revisão pela gerência. Cada requisito desses contém determinadas especificações. Conforme a ABNT (2004) quanto à política ambiental respectivamente, a alta administração deve definir a política ambiental da organização e assegurar que ela:

a) Seja apropriada a natureza, escala e impactos ambientais de suas atividades, produtos ou serviços;

b) Inclua o comprometimento com a melhoria continua e com a prevenção da poluição;

c) Inclua o comprometimento com o atendimento á legislação e ás normas ambientais aplicáveis

e aos demais requisitos subscritos pela organização;

d) Forneça a estrutura para o estabelecimento e a revisão dos objetivos e das metas ambientais;

e) Seja documentada, implementada, mantida e comunicada a todos os empregados;

f) Esteja disponível para o público.

Seiffert (2002, p.9 apud SOUSA et al, 2011) comenta que a evolução das iniciativas ambientais nas organizações trouxe a necessidade de a gestão ambiental ser tratada enquanto sistema. "Um SGA têm entre seus elementos integrantes uma política ambiental, o estabelecimento de objetivos e metas, o monitoramento e medição de sua eficácia, a correção de problemas associados à implantação do sistema, além de sua análise e revisão como forma de aperfeiçoá-lo", o que vem a melhorar o desempenho ambiental geral.

Sendo assim Pinheiro e Oliveira (2010) explicam que é importante que a organização tenha uma pessoa responsável para coordenar e supervisionar o andamento dos processos. Nesse sentido, a área de recursos humanos, pode contribuir para o bom desempenho do SGA por favorecer o desenvolvimento das ferramentas necessárias para a gestão das competências ambientais provendo informações 
gerenciais, relatórios executivos e sumários para a alta direção (PINHEIRO E OLIVEIRA, 2010).

\subsection{GeStÃo AMBIENTAL EMPRESARIAL}

Segundo Barbieri (2006), para as empresas deixarem de serem problemas para o meio ambiente e sejam soluções, é exigido que empresários e administradores estabeleçam uma nova atitude, que deve passar a considerar o meio ambiente em suas decisões e adotar concepções administrativas e tecnológicas que contribuam para ampliar a capacidade de suporte do planeta.

Dias $(2009$, p.84) considera as empresas um dos principais agentes para a efetivação de um desenvolvimento sustentável. Para isso se faz necessário que haja aceitação e comprometimento em seu ambiente interno com a adoção de um SGA conduzindo a uma mudança na cultura organizacional, tendo o componente ambiental entre as preocupações da população interna.

Quadro 1 - Conjuntos de forças que influenciam as preocupações com o meio ambiente

\begin{tabular}{|c|l|}
\hline Governo & $\begin{array}{l}\text { Construção de legislações ambientais impulsionados pela sociedade. Responsável ainda pela } \\
\text { fiscalização e penalização das organizações que não seguem as leis e normas estabelecidas. }\end{array}$ \\
\hline Sociedade & $\begin{array}{l}\text { As organizações da sociedade civil que atuam nas áreas ambientais e sociais tornando-se uma } \\
\text { influência poderosa da formação de opiniões perante o grande público, de pressões políticas } \\
\text { nas instâncias legislativas e executivas e de cooperação com as empresas. }\end{array}$ \\
\hline Mercado & $\begin{array}{l}\text { As questões ambientais passaram a ter impactos importantes sobre a competitividade dos } \\
\text { países e de suas empresas. Pois a intensificação dos processos de abertura comercial expondo } \\
\text { produtores com diferenças pronunciadas de custos ambientais e sociais a uma competição } \\
\text { mais acirrada e de âmbito mundial tem sido uma poderosa força indutora de regulamentação } \\
\text { e auto-regulamentação socioambientais. }\end{array}$ \\
\hline
\end{tabular}

Fonte: adaptado de Barbieri (2006)

Para a empresa que se preocupa em implantar a gestão ambiental em sua cultura organizacional, suas ações iniciais de mudança devem concentrar-se na cultura interna da organização, ou seja, começar a nova postura ambiental de dentro para fora. Trabalhando diretamente na conscientização de todos seus colaboradores, desde o operário de chão de fabrica até o executivo do mais alto escalão. Desse modo, toda a equipe de trabalho estará preparada para atender as mudanças culturais e operacionais necessária para uma gestão ambiental empresarial eficaz.

Conforme Barbieri (2006), as preocupações ambientais dos empresários são influenciadas por três grandes conjuntos de forças que se interagem reciprocamente: o governo, a sociedade e o mercado, conforme apresentado do quadro 1.

A partir do exposto no Quadro 1 percebe-se que se não houvesse pressões da sociedade e medidas governamentais não se observaria o crescente envolvimento das empresas no aspecto ambiental. "A administração ambiental está associada à ideia de resolver os problemas ambientais da empresa. Ela carece de uma dimensão ética e suas principais motivações são a observância das leis e a melhoria da imagem da empresa" (TACHIZAWA, 2006, p.12). Sendo assim, considera-se que as políticas públicas são as grandes motivadoras que levam as empresas adotarem um modelo de gestão ambiental, o que acarretará em uma produção mais limpa.

O principio básico de Produção Mais Limpa consiste em reduzir ou eliminar a poluição durante o processo de produção e não no seu final, pois todos resíduos que uma empresa está pagando para tratar e armazenar tem um custo no início e continuará a ter no fim (KRAEMER, 2002).

De acordo com o PNUMA apud Dias (2009, p. 127), o programa para a Produção Mais Limpa busca:

- Aumentar o consenso mundial para uma visão de produção mais limpa;

- Apoiar a rede de organizações dedicadas à promoção de estratégias de produção mais limpa

e à eco-eficiência;

- Ampliar as possibilidades de melhoria ambiental das empresas mediante a capacitação e a educação; 
- Apoiar projetos que sirvam de modelo de referencia;

- Fornecer assistência técnica.

Desse modo, a implantação de um sistema de Produção Mais Limpa para qualquer tipo de empresa e organização é uma alternativa que deve ser considerada de suma importância, é através de uma análise dos objetivos que esse modelo de produção procura atingir. É possível verificar que a empresa/organização e meio ambiente, só tem a ganhar, pois o mesmo elimina ou reduz os desperdícios e previne a contaminação do meio ambiente.

\section{APRESENTAÇÃO E ANÁLISE DOS DADOS}

Em resposta aos objetivos propostos, a seguir apresenta-se a análise e discussão dos resultados. Primeiramente faz-se um breve histórico da empresa em estudo e perfil do gestor, em seguida dados resultantes da entrevista realizada na primeira etapa da pesquisa, após, os resultados obtidos na segunda etapa junto aos colaboradores, por meio de questionário. A partir desses, ao final apresenta-se a proposta de um sistema de gestão ambiental para a empresa.

\section{I DADOS DO CENTRO AUTOMOTIVO E PERFIL DO GESTOR}

O Centro Automotivo em estudo é localizado na cidade de Santa Maria/RS inserido no mercado desde 1963, ano que iniciou suas atividades com consertos de equipamentos agrícolas, caminhões e automóveis, e serviço de jato de areia em peças e estruturas metálicas passando a atuar no comércio de autopeças, e serviços direcionado ao conserto de automóveis no ano de 1985, tendo, portanto 40 anos de atuação no mercado. No que diz respeito a marca e o porte de veículos, a empresa trabalha com multimarcas de veículos da linha leve, compreendendo veículos nacionais e importados. Possui um quadro de 13 colaboradores para realizar suas atividades e 1.997 clientes cadastrados no seu banco de dados entre pessoas físicas e jurídicas.

O proprietário da empresa é filho do fundador, possui 47 anos, tem o ensino médio completo, e todo seu tempo de serviço foi dedicado a esta empresa, e é responsável pela gerência da mesma.

\section{I.I Práticas de gestão ambiental}

A primeira questão relacionada sobre o posicionamento da empresa no que diz respeito à gestão ambiental, o entrevistado afirmou que: "A empresa procura na medida do possível evitar danos ao meio ambiente, procurando fazer o serviço produzindo o mínimo de lixo, estamos sempre preocupados em proteger o meio ambiente, porém, o governo deveria comprometer-se em investir junto com as empresas no recolhimento dos resíduos produzidos".

Sendo assim, foi possível identificar por parte do proprietário uma gestão que inclui preocupações ambientais, ou seja, há interesse em proteger o meio ambiente, dentro de suas capacidades físicas e financeiras.

A partir da resposta ao questionamento sobre a adoção de algum procedimento ou cuidado com intuito de preservar o meio ambiente ou reduzir possíveis danos a natureza, quais resíduos são gerados pela empresa e qual o destino final de cada um deles, elaborou-se o quadro 2.

Com o exposto no Quadro 2, percebe-se que o proprietário da empresa realmente está preocupado em evitar danos à natureza.

Quando questionado se considera importante para as empresas do ramo automobilístico implementar algum tipo de SGA e o por quê, a resposta do proprietário foi a seguinte: "Sim, para diminuir o lixo produzido e dar um destino correto, que cause menos dano ao meio ambiente, além da possibilidade de conseguir algum ganho financeiro com a venda de materiais recicláveis".

\subsection{Perfil do Colaboradores}

Todos entrevistados são do sexo masculino, possuem em média 31 anos. No que diz respeito à escolaridade três possuem ensino fundamental, seis possuem ensino médio completo e três estão com o ensino superior incompleto. No que diz respeito a função, há sete mecânicos, um chapeador responsável pela execução dos serviços de lanternagem e pintura dos automóveis, dois auxiliares de mecânicos e dois auxiliares de escritório. Em relação ao tempo de serviço sete colaboradores possuem 
Quadro 2 - Procedimentos adotados para os resíduos e seus benefícios

\begin{tabular}{|l|l|}
\hline \multicolumn{1}{|c|}{ Procedimento } & \multicolumn{1}{c|}{ Benefício } \\
\hline $\begin{array}{l}\text { Separação do material reciclável como } \\
\text { papel, papelão, plástico, vidro, e outros. }\end{array}$ & $\begin{array}{l}\text { Recolhimento para um destino apropriado de } \\
\text { cada material. }\end{array}$ \\
\hline $\begin{array}{l}\text { Construção de uma caixa de separação de } \\
\text { óleo e impurezas que se misturam na água } \\
\text { após a lavagem de peças e veículos. }\end{array}$ & $\begin{array}{l}\text { Escoamento de água mais limpa, diminuindo } \\
\text { a poluição dos rios e da natureza. }\end{array}$ \\
\hline $\begin{array}{l}\text { Encaminhamento do óleo e impurezas que } \\
\text { ficam armazenados na caixa juntamente } \\
\text { com o óleo queimado das trocas de óleo. }\end{array}$ & $\begin{array}{l}\text { Destinação apropriada de resíduos por meio } \\
\text { de uma empresa terceirizada que possui } \\
\text { caminhões apropriados para o transporte e } \\
\text { recolhimento. }\end{array}$ \\
\hline $\begin{array}{l}\text { Separação de materiais como embalagens } \\
\text { de óleo, panos, filtros usados, jornais e } \\
\text { papelão sujos com óleo. }\end{array}$ & $\begin{array}{l}\text { Recolhimento por meio de empresa } \\
\text { especializada dando um fim mais correto o } \\
\text { que antes não ocorria. }\end{array}$ \\
\hline
\end{tabular}

menos de quatro anos de empresa, o restante possui de quatro a 20 anos de contrato.

\subsection{Adoção de práticas em benefício do meio ambiente}

$\mathrm{Na}$ percepção dos colaboradores no que diz respeito ao cumprimento por parte da empresa das normas e exigências legais relacionadas ao meio ambiente, três responderam que "sim" a empresa cumpre com as normas e exigências legais, dois assinalaram que "não" e os sete restantes marcaram a opção que indica "em parte". Desse modo, podemos verificar que a empresa não procura deixar claro, ou bem informado seus colaboradores sobre os procedimentos e atitudes que ela utiliza para cumprir com as normas e com as exigências legais relacionadas ao meio ambiente.

Para identificar os principais resíduos gerados pela empresa, e verificar qual o destino final de cada um deles conforme a percepção dos colaboradores foi elaborada uma tabela a partir das respostas dos entrevistados. Além de pesquisa em artigos e trabalhos científicos realizados em empresas do mesmo seguimento, conforme Tabela 1.

A partir do exposto na Tabela 1 tem-se que dos 18 resíduos listados, os colaboradores possuem clareza da destinação de apenas dois, do processo de pintura em que $100 \%$ assinalou a opção "Outras formas" e óleo queimado no qual 100\% assinalou a opção "Empresa especializada". Outros materiais como: borrachas, peças contaminadas com óleo ou graxa e principalmente vidros não contam com uma percepção clara de seus descartes por parte dos colaboradores.

Conforme os resultados dessa questão foi possível perceber uma grande disparidade de informações a respeito do conhecimento sobre o destino final dos materiais descartados pela empresa, enquanto era esperado um destino para cada resíduo, teve casos em que um mesmo resíduo apresentava diversos destinos.

Apesar disso, ao perguntar aos colaboradores do Centro Automotivo sobre a importância de um correto destino para os resíduos, as respostas foram semelhantes em afirmar que é fundamental, conforme afirmou um dos colaboradores "Sim, devemos nos preocupar em preservar o meio ambiente a fim de termos garantia para nossos filhos e para as futuras geraçôes ficarem asseguradas de terem uma vida saudável, principalmente em relação a água e o ar".

E o porquê dessa atitude também teve respostas praticamente idênticas, ou seja, todos respondentes estão conscientes que é preciso preservar o meio ambiente para assegurar a qualidade de vida e das futuras gerações, assim como manter os recursos naturais em condições saudáveis. Diante desse fato o referido estudo irá sugerir um sistema de gestão ambiental a empresa no intuito de contribuir na melhoria dos processos de resíduos.

\subsection{SisTEMA DE GESTÃO AMBIENTAL: UMA PROPOSTA PARA O CENTRO AUTOMOTIVO}

Após análise das informações coletadas sobre a gestão ambiental no Centro Automotivo verificou-se a necessidade de melhorias nos processos relacionados ao descarte de resíduos. Sendo assim, 
Tabela 1 - Destino dos resíduos (\%) produzidos pela empresa segundo os entrevistados

\begin{tabular}{l|c|c|c|c|c}
\hline \multicolumn{1}{c|}{ Resíduo } & $\begin{array}{c}\text { Coleta } \\
\text { pública }\end{array}$ & $\begin{array}{c}\text { Catadores } \\
\text { (doação) }\end{array}$ & $\begin{array}{c}\text { Ferro } \\
\text { velho }\end{array}$ & $\begin{array}{c}\text { Empresa } \\
\text { especializada }\end{array}$ & $\begin{array}{c}\text { Outras } \\
\text { formas }\end{array}$ \\
\hline 1. Alumínio & & & 83 & 17 & \\
\hline 2. Borrachas & 58 & 17 & & 8 & 17 \\
\hline $\begin{array}{l}\text { 3. Estopas e panos de limpeza } \\
\text { usados }\end{array}$ & & & & 92 & 8 \\
\hline 4. Embalagens de óleo/graxa & 8 & & & 84 & 8 \\
\hline 5. Ferro & & & 92 & 8 & \\
\hline 6. Lâmpadas fluorescentes & 67 & & & 8 & 25 \\
\hline 7. Madeira & 33,3 & 16,6 & & & 41,7 \\
\hline 8. Papel e papelão & 16,6 & 83,4 & & & \\
\hline $\begin{array}{l}\text { 9. Peças contaminadas com graxa } \\
\text { ou óleo }\end{array}$ & 8,4 & & 33,3 & 33,3 & 25 \\
\hline 10. Peças usadas & & & 91,6 & 8,4 & \\
\hline 11. Pilhas e baterias & & & & 75 & 16,6 \\
\hline 12. Plástico & 41,6 & 50 & & 8,4 & \\
\hline 13. Pneus & & & & 50 & 41,6 \\
\hline $\begin{array}{l}\text { 14. Óleo resultante da lavagem de } \\
\text { peças e motores }\end{array}$ & & & & 67 & 33 \\
\hline 15. Óleo queimado & & & & & 100 \\
\hline $\begin{array}{l}\text { 16. Resíduos do processo de } \\
\text { pintura }\end{array}$ & & & & & 100 \\
\hline 17. Solventes & 41,6 & 8,4 & & 25 & 25 \\
\hline 18. Vidro & & & & \\
\hline
\end{tabular}

essa pesquisa irá propor um sistema de gestão ambiental simples e de acordo com a realidade física e financeira da organização, baseando-se no descarte final correto de cada resíduo gerado pela empresa.

Retomando a revisão da literatura, Barbieri (2006) relata que uma empresa pode criar o seu próprio SGA ou adotar um dos modelos genéricos propostos por entidades nacionais ou internacionais. A criação e a operação de um SGA podem ser consideradas uma espécie de acordo voluntário unilateral, desde que a empresa se comprometa a alcançar um desempenho superior ao exigido pelas leis ambientais.

Contudo, tem-se uma proposta que o Centro Automotivo poderá seguir para melhorar seu desempenho ambiental referente aos principais resíduos gerados.

Óleo queimado, óleo resultante da lavagem de peças e motores, solventes e as baterias que tem o armazenamento, transporte e destino final apropriado, ou seja, cumpre com as exigências legais, necessitam apenas de uma manutenção nos depósitos, e treinamento dos colaboradores sobre todo processo de acondicionamento até o destino final.

Alumínio: aconselha-se que a empresa separe esse material, pois o mesmo é descartado junto com o ferro velho. Logo, seria aconselhável a venda para uma empresa especializada que realize a reciclagem, obtendo até um pequeno lucro com essa atitude.

Estopas e panos de limpeza usados: esses resíduos altamente poluidores devem ser acondicionados em tonéis de plástico, e estocados em local coberto para seu destino final no Aterro para Resíduos Perigosos (ARIP) ou incineração. Apesar desse procedimento gerar um custo para empresa, ela receberá comprovantes que garantirão a legalidade perante a lei, caso venha ocorrer uma fiscalização. De acordo com ABNT NBR 10004 esses resíduos são de classe I - Perigosos, sendo que suas características são: inflamabilidade, corrosividade, reatividade, toxicidade e patogenicidade.

Embalagens de óleo e graxa: propõe-se que o gestor contate uma empresa especializada para 
recolher esses resíduos, sendo que para esse não acarretará custos e o destino final será a reciclagem.

A mesma empresa especializada que realiza o recolhimento desses resíduos podem recolher todos outros que não foram citados, como: borrachas, lâmpadas fluorescentes, peças contaminadas com lubrificantes, pneus para um destino final apropriado.

Referente aos resíduos do processo de pintura, o procedimento é mais delicado pois tem um custo alto para empresa, envolve uma série de modificações no local onde é realizado o serviço, além da compra de equipamentos. Sendo assim cabe a empresa avaliar a viabilidade da implementação do sistema de coleta de resíduos do processo de pintura.

Outro aspecto importante para o sucesso de um SGA é o treinamento de seus colaboradores sobre a importância de seguir um procedimento, deixando claro e bem informado sobre como deve ser os processos de acondicionamento, transporte e qual o destino final de cada resíduo.

Embora a implementação de um SGA traga despesas para a empresa, é importante que seja feita uma relação desses custos com todos os benefícios proporcionados pelo SGA.

\section{CONSIDERAÇÕES FINAIS}

A presente pesquisa permite inferir que para as empresas do setor automobilístico o compromisso com o meio ambiente deve ter um cuidado redobrado, pois os resíduos gerados em seus processos são considerados perigosos para natureza e consequentemente aos seres vivos. Esse estudo, portanto teve por objetivo geral identificar a aplicabilidade de um programa de gestão ambiental em um Centro Automotivo localizado na cidade de Santa Maria/RS.

A partir dos resultados constatou-se que o gestor da empresa não tem muito conhecimento sobre os benefícios que a implementação de um SGA pode trazer, entretanto, demonstrou interesse na sua aplicabilidade quando afirmou: "Sim, já exercemos os que estão ao nosso conhecimento e se existirem outros métodos gostaríamos de colocar em prática". Essa adesão se faz importante, como aponta Gomes, Jabur \& Freitas (2010) o reconhecimento, por parte do gestor da empresa, da gestão ambiental como um valor é uma das etapas necessárias para inserção do sistema.

A empresa mostra-se preocupada em preservar o meio ambiente, pois procura realizar o descarte de seus resíduos considerando suas preocupações ambientais, ainda assim dos dezoito resíduos identificados apenas dois possuem descarte amplamente conhecido pelos colaboradores isso mostra que ou não existe um planejamento ou fluxograma para que os colaboradores possam saber qual deve ser o destino final de cada resíduo, ou a empresa ainda não determinou um fim apropriado a cada um eles.

Segundo Avila et al (2013) pelo fato das organizações serem formadas por pessoas faz-se necessário que essas se conscientizem da importância de uma atuação mais responsável e preocupada com as questões ambientais para que a gestão ambiental possa ter valor na organização por meio do empenho de todos.

A implementação de um SGA proporcionaria um ambiente de trabalho muito mais limpo e seguro aos funcionários, podendo até melhorar a produtividade e redução quanto ao risco de acidentes, pois diversos resíduos apresentam características que facilitam esses inconvenientes. Haveria também uma redução no impacto negativo que o descarte inapropriado de resíduos causa no meio ambiente e conformidade perante as leis ambientais já existentes.

Essa constatação vem de encontro com o estudo de Naime, Andara \& Santos (2010) em que apontam, dentre outros, como benefícios da implantação do SGA: melhor imagem institucional junto aos clientes, fornecedores, colaboradores e a comunidade, redução na geração de resíduos, garantia do atendimento às legislações e regulamentações, melhor preparo para enfrentar situações de emergência e melhorias quanto à segurança no trabalho, entre outros.

Embora esse estudo tenha indicado algumas sugestões para o centro automotivo quanto ao melhoramento de desempenho ambiental referente aos principais resíduos gerados, sua limitação reside na decisão da empresa em verificar a viabilidade e os benefícios que a implementação de um SGA pode proporcionar, pois sua utilização compreende procedimentos padronizados e adequados a todos resíduos.

Visto a relevância das informações adquiridas com a elaboração dessa pesquisa, seria interessante a continuidade de seus estudos por acadêmicos ou organizações que pretendem dissipar a consciência ecológica e também diferenciar-se no mercado contemporâneo. 


\section{REFERÊNCIAS}

[ABNT] ASSOCIAÇÃO BRASILEIRA DE NORMAS TÉCNICAS. NBR ISO 14001: 2004 Sistemas de gestão ambiental - Requisitos de orientação para uso: ABNT 2004.

ANDRADE, R O. B.; TACHIZAWA, T.; CARVALHO, A. B. Gestão Ambiental: Enfoque Estratégico Aplicado ao Desenvolvimento Sustentável. $2^{\circ}$ Ed. São Paulo: Pearson Makron Books, 2002.

AVILA, L. V.; MADRUGA, L. R. R. G.; ROCHA, A. C.; CAMARGO, C. R. Análise das estratégias de gestão ambiental em empresas do setor industrial. Revista Capital Científico - Eletrônica (RCCe), v. 1,1 n., jan- jun/2013. Disponível em: <http://eds.a.ebscohost.com/ehost/pdfviewer/pdfviewer?sid=54d7d501-3ee44899-bb33-9290e4786552\%40sessionmgr4003\&vid=1\&hid=4113> Acesso em: 31 mar, 2014.

BARBIERI, J. C. Gestão Ambiental Empresarial: conceitos, modelos e instrumentos. São Paulo: Editora Saraiva, 2006.

CAMPOS, L. M. S.; MELO, D. A.; SILVA, M. C.; FERREIRA, E. Os sistemas de gestão ambiental: empresas brasileiras certificadas pela norma ISO 14001. In: XXVI ENEGEP, Fortaleza, 2006.

CERVO, A. L.; BERVIAN, P. A.; SILVA, R. Metodologia científica. $6^{\circ}$ Ed. São Paulo: Pearson Prentice Hall, 2007.

CORAZZA, R. I. Gestão Ambiental e Mudanças da Estrutura Organizacional. Revista de Administração de Empresas. RAE-eletrônica, v. 2, n. 2, jul-dez/2003. Disponível em: <http://www.scielo.br/pdf/raeel/v2n2/ v2n2a06.pdf> Acesso em: 31 mar, 2014.

GOMES, P. G.; OLIVEIRA, V. B. P; NASCIMENTO, E. A. Aspectos e impactos no descarte de óleos lubrificantes: o caso das oficinas. In: IV CONGRESSO NACIONAL DE EXCELÊNCIA EM GESTÃO. Niterói, 2008, p.15. Disponível em: < http://www.excelenciaemgestao.org/Portals/2/documents/cneg4/anais/ T7_0035_0236.pdf > Acesso em: 31 mar, 2014.

DIAS, R. Gestão Ambiental: Responsabilidade Social e Sustentabilidade. São Paulo: Editora Atlas S.A., 2009.

DONAIRE, D. Gestão Ambiental na Empresa. 2 Ed. São Paulo, Editora Atlas S.A., 2009.

GIL, A. C. Estudo de Caso. São Paulo: Atlas, 2009.

Como elaborar projetos de pesquisa. $4^{\circ}$ ed. São Paulo: Atlas, 2008.

GOMES, A. F.; JABBOUR, C. J. C.; FREITAS, W. R. S. Gestão Ambiental: Um novo desafio para os profissionais de recursos humanos? Revista Cesumar - Ciências Humanas e Sociais Aplicadas, v. 16, n. 1, jan./jun. 2011, p. 29-47. Disponível em: <http://www.cesumar.br/pesquisa/periodicos/index.php/revcesumar/article/ viewFile/1176/1215> Acesso em: 31 de mar, 2014.

KÖCHE, J. C. Fundamentos de metodologia científica: teoria da ciência e prática da pesquisa. 15. Ed. Petrópolis, RJ: Vozes, 1997.

KRAEMER, T. H. Modelo Econômico de Controle e Avaliação de Impactos Ambientais - MECAIA. 2002. 191f. Tese (Doutorado) - Universidade Federal de Santa Catarina, Florianópolis, 2002.

YIN, R. K. Estudo de Caso: planejamento e métodos. $3^{\circ}$ Ed. Porto Alegre: Bookman, 2005.

MARCONI, M. A.; LAKATOS, E. M. Fundamentos de Metodologia Científica. $7^{\circ}$ Ed. São Paulo, Editora Atlas S.A., 2010. 
Fundamentos de Metodologia Científica. $6^{\circ}$ Ed. São Paulo, Editora Atlas S.A., 2007.

NAIME, R. H.; ANDARA, S.; SANTOS, K. L. Benefícios da implantação do Sistema de Gestão Ambiental na Indústria. Revista Cesumar - Ciências Humanas e Sociais Aplicadas, v. 15, n. 1, jan./jul. 2010, p. 11-33. Disponível em: <http://www.cesumar.br/pesquisa/periodicos/index.php/revcesumar/article/viewArticle/1063> Acesso em: 31 mar, 2014.

OLIVEIRA, O. J. ; PINHEIRO, C. R. M. S. Implantação de sistemas de gestão ambiental ISO 14001: uma contribuição da área de gestão de pessoas. Revista Gestão \& Produção, São Carlos, v. 17, n. 1, p. 51-61, 2010. Disponível em: < http://www.scielo.br/pdf/gp/v17n1/v17n1a05.pdf> Acesso em: 31mar, 2014.

REIS, L. F. S. de S. D.; QUEIROZ, S. M. P. Gestão Ambiental em Pequenas e Médias Empresas. $1^{\circ}$ Ed. Rio de Janeiro, Editora Norte Rio Gráfica, 2002.

SOUZA, N. G.; PASQUALETTO, A. ; RESENDE, V. Abordagem Sistêmica da Implantação da Nbr Iso 14001 na Concessionária Lince Veículos Sa - Goiânia. Disponível em <http://www.ucg.br/ ucg/prope/cpgss/ArquivosUpload/36/file/Continua/ABORDAGEM\%20SIST\%C3\%8AMICA\%20 DA\%20IMPLANTA $\%$ C3\%87\%C3\%83O\%20DA $\% 20$ NBR\%20ISO $\% 2014001 \% 20$ NA $\% 20$ CONCESSION\%C3\%81RIA\%20LINCE\%20VE\%C3\%8DCULOS_.pdf > Acesso em: mar, 2014.

TACHIZAWA, T. Gestão Ambiental e Responsabilidade Social Corporativa: Estratégias de Negócios Focadas na Realidade Brasileira. $6^{\circ}$ Ed. São Paulo, Editora Atlas S. A., 2009.

TRIVIÑOS, A. N. S. Introdução à Pesquisa em Ciências Sociais: A Pesquisa Qualitativa em Educação. $1^{\circ}$ Ed. São Paulo, Editora Atlas S. A., 2007.

WENDLER, D. F. Sistema de Gestão Ambiental Aplicado a uma Vinícola: Um Estudo de Caso. 2009. 176 f. Dissertação (Mestrado) - Universidade Federal de Santa Maria, Santa Maria, 2009. Disponível em: <http:// www.senairs.org.br/cntl/ > Acesso em: 26 set. 2010, 13:56.

RELATÓRIO DO ESTADO DO MEIO AMBIENTE 2013. Rea 2013: Portugual. Portugual, 2013, p. 185. Disponível em: <http://www.apambiente.pt/_zdata/DESTAQUES/2013/REA_2013_Final_30dezembro.pdf $>$ Acesso em: 21 jan. 2014.

TRIGUEIRO, A. Mundo sustentável: abrindo espaço na mídia para um planeta em transformação. Rio de Janeiro: Globo, 2005. p. 102. 